\title{
FUNGITOXIC PROPERTIES OF FOUR CRUDE PLANT EXTRACTS ON FUSARIUM OXYSPORUM SCHL. F. SP PHASEOLI
}

\section{Obongoya $\mathrm{BO}^{1 *}$, Wagai $\mathrm{SO}^{2}$ and G Odhiambo ${ }^{3}$}

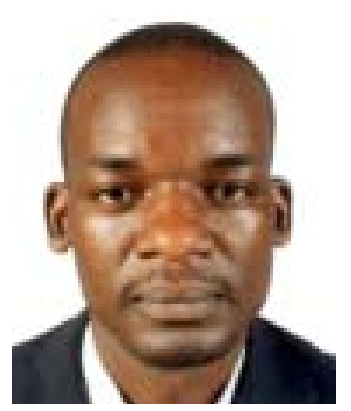

Obongoya Bonventure

*Corresponding author email: obongoya@yahoo.com

${ }^{1}$ Department of Resource Surveys and Remote Sensing, P.O. Box 471467-00100 Nairobi, Kenya.

${ }^{2 \& 3}$ Department of Botany and Horticulture, Faculty of Science, Maseno University Private Bag Maseno, Kenya. 


\section{ABSTRACT}

Fusarium yellows is a disease of common beans (Phaseolus vulgaris, L.) caused by Fusarium oxysporum Schl. F. sp. phaseoli, it has been found to be important in Busia district of Western province, Kenya. The study on fungitoxic properties of four locally available crude plant extracts was aimed at evaluating their efficacy in controlling Fusarium yellows infestation under the field conditions. Crude plant extracts from Azadirachta indica, Tagetes minuta, Nicotiana tobacum and Vinca rosea were tested against Fusarium oxysporum Schl. F. sp. phaseoli. Participatory On-Farm Trials (POFT) in six (6) divisions were carried out in August-September 2005 and MarchJune 2006; a total of thirty (30) farms were randomly surveyed. Minimum Inhibitory Concentration (MIC) of crude plant extracts against Fusarium was determined by broth microdilution method. Analysis of variance (ANOVA) was performed on the data, using Genstat $8^{\text {th }}$ edition statistical program (Release 8.11, Lawes Agricultural Trust, Rothamsted Experimental Station, Harpenden, UK). Means were separated using LSD. Crude plant extracts exhibited fungitoxic activity against Fusarium oxysporum Schl. F. sp. phaseoli, with varying degree of efficacy. Nicotiana tobacum and Vinca rosea were not effective, Azadirachta indica and Tagetes minuta exhibited significant control over Fusarium. Azadirachta indica performed better amongst all the plant extracts. Common bean treatment with Benomyl 1 significantly reduced $(\mathrm{P} \leq 0.05)$ wilt incidence and increased growth in comparison to negative (-ve) control. Azadirachta indica formulation gave a significant reduction in wilt incidence compared to the other three crude plant extracts formulations. It reduced the wilt incidence by $17.24 \%$ in comparison to Tagetes minuta, Nicotiana tobacum and Vinca rosea whose wilt incidence reduction ranged from 5.84-9.8\%. Azadirachta indica inhibited Fusarium growth at lower dosage than Tagetes minuta, Nicotiana tobacum and Vinca rosea. Extracts from Azadirachta indica and Tagetes minuta are effective, cheap and ecofriendly promising methods for protecting common bean against Fusarium oxysporum Schl. F. sp. phaseoli.

Key words: Ecofriendly, Efficacy, Plant extracts, Fusarium oxysporum

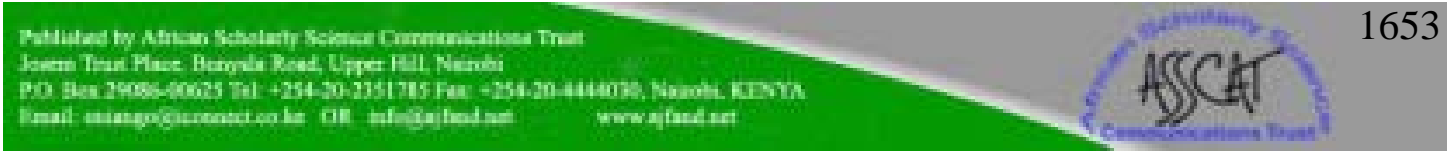




\section{INTRODUCTION}

Common bean (Phaseolus vulgaris L.) is an important food and cash crop particularly in Eastern, Southern and Great lake region [1]. It is considered to be the second most important source of human dietary protein (after maize) and third most important source of calories after maize and cassava [2]. The common bean is grown by more than $90 \%$ of the population worldwide, mostly by small scale farmers for home consumption, with some selling the surplus to meet domestic financial requirements [3]. It is the main source of affordable protein for rural and urban households and for institutions such as hospitals, schools and the army [4]. Compared to other pulses, the common bean is the most widely grown pulse in Kenya, found in most of the districts with production decreasing towards Coast and Northern parts of the country.

A survey conducted in central province of Kenya in 1980 revealed a high percentage incidence of Fusarium yellows in all districts where beans are grown but most seriously in Muranga and Kiambu where significant reduction in yields was also reported [5]. In western Kenya the incidence was noted to be high in Busia, Vihiga and Kakamega [6]. Diseases such as anthracnose, angular leaf spot, bean rust, bean scab, sclerotinia rot and common bean mosaic virus are some of important bean diseases that have received attention, but little has been done to control Fusarium yellows caused by Fusarium oxysporum Schl. F. sp. phaseoli. Economic losses in yield due to Fusarium oxysporum Schl. F.sp. phaseoli was first reported by Kendrick \& Snyder in 1942 in Colorado [7] and subsequently in Egypt [8], Colombia [9], Brazil [10], Central Africa [11] and Kenya [5]. Synthetic chemical fungicides are being used successfully for the control of Fusarium oxysporum Schl. F. sp. phaseoli but indiscriminate use of these chemicals has led to the development of fungicide resistance and more importantly, environmental pollution, posing potential risk to animal and human health [12].

The four selected plants are locally available in sufficient quantities. Scientific studies have revealed that the four plants can control a number of fungal pathogens in vivo [13]. Their active ingredients content ranges from moderate to high, making them potential candidates for On Farm Trials (OFT). The major setback in the control of Fusarium oxysporum Schl. F. sp. phaseoli in the study area has been low per capita income; with household poverty incidence among subsistence farmers in the district being $68.2 \%$, even though it is classified as high potential zone in terms of Agricultural productivity [14]. This situation has hindered small-scale subsistence farmers' ability to acquire synthetic chemicals to control this fungal infection of beans. This whole scenario, therefore, calls for alternative approaches for the control of soil borne pathogens. The approach need to be economically feasible and ecofriendly to eliminate or reduce the incidence of this economic pathogen, so as to increase yield of common bean. The leaves, flowers, seeds and twigs were used to yield 'concentrated' extract due to the fact that they contain high level of active ingredients needed for pathogen control

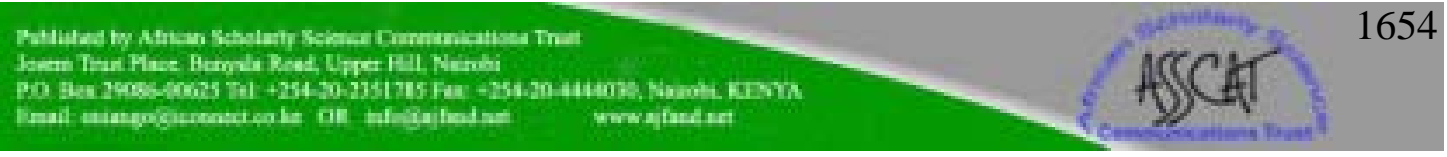


This paper reports the fungitoxic activity of four locally available plant species against Fusarium oxysporum Schl. F. sp. phaseoli.

\section{MATERIALS AND METHODS}

The study was conducted in Busia district, western part of Kenya in the field during two rainy seasons of 2005 and 2006. The district receives $1150 \mathrm{~mm}$ of rainfall annually on average and experiences an average of a maximum temperature of $26^{\circ} \mathrm{C}$ and a minimum of $16^{\circ} \mathrm{C}$ [15]. Bean-growing sites in Busia municipality, Budalangi, Matayos, Funyula, Nambale and Butula divisions were used during this study.

\section{Pathogen identification}

Pathogen identification was done in Commonwealth Agriculture Bureau International (CABI) Laboratory, Nairobi and Botany Laboratory at Maseno University, Kenya. In Botany Laboratory at Maseno University, Kenya; five plants were uprooted from each of the surveyed farm and dried in plant press for isolation experiments. Diseased plant specimens were isolated to confirm the identification of the pathogens present.

Potato Dextrose Agar (PDA) was used for the isolation, PDA slants in Mcartney bottles loosely screwed with caps fitted with an inner rubber lining and sterilized by autoclaving at $121^{\circ} \mathrm{C}$ at one bar gauge pressure $\left(10 \mathrm{~N} / \mathrm{m}^{2}\right)$ for 15 minutes and left to cool a little then placed in a slanting position, forming a sloping medium surface were used to subculture pure Fusarium oxysporum fungus.

Pure Fusarium oxysporum Schl. F sp. phaseoli fungus prepared in Botany Laboratory at Maseno University was allowed to grow for 10 days at CABI Laboratory. To induce conidiation Carnation Leaf Agar (CLA) media was used [16]. For microscopic observation, Fusarium was grown on CLA at $25^{\circ} \mathrm{C}$ for 5 days, and agar blocks $(\sim 2 \times 2$ $\mathrm{mm}$ ) containing fungal propagules were cut out from the media. They were attached onto specimen stubs, frozen in liquid nitrogen, and observed with a scanning microscope (S-4000, Hitachi, Ibaraki, Japan) after gold coating.

Fusarium oxysporum Schl. F sp. phaseoli penetrates into the host through the root or the hypocotyls but the presence of wounds may be necessary in order to permit penetration into exposed xylem vessels. The fungus grows principally inside the vascular elements causing discoloration and browning of the affected areas. Subsequent deposits of gum-like materials can cause plugging of the vascular system. To cause wilt, the fungus must also establish in the xylem and induce tracheomylosis a process completed only by the strain specialized for that host plant [17]. The severity of the disease depends on inoculum's density and soil type with some soils being more suppressive than others [18].

Sandy soils are more conducive in spreading wilt than loams or clays; this is due to better drainage in former. Fusarium wilt has also been reported to be more severe in

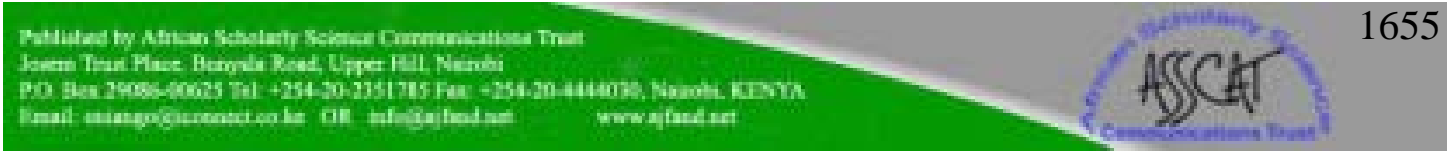


wet rather than in dry soils. The fungus penetrates the base and invades the xylem vessels. The plugging of the vessels by the fungal mycelium and in some cases production of toxins results in wilting symptoms in some plants and yellowing of leaves and shoots in others.

With the occurrence of unfavourable conditions and in the absence of a host, the fungus forms chlamydospores in the soil [19].

Chlamydospores are hyphal or spore cells with thickened cell walls and which are resistant to adverse physical and chemical conditions. Germination of chlamydospores is stimulated by nutrients from the host root exudates or by extraneous food base introduced into the soil.

\section{Plant material}

Azadirachta indica (Neem tree), Tagetes minuta (Mexican marigold), Nicotiana tobacum (Tobacco) and Vinca rosea (Peri winkle) materials were collected from the wild in Budalangi and Butula areas of Busia district. Taxonomic authentification of plant specimens was performed by taxonomist at Department of Botany-Herbarium and Botanic garden, Maseno University, Kenya.

Crude plant extracts evaluated comprised of Azadirachta indica, Tagetes minuta, Nicotiana tobacum and Vinca rosea and Benomyl 1 was used as control. Plant parts were harvested from mature plants at random by either uprooting entire plant (Tagetes minuta, Nicotiana tobacum and Vinca rosea) or plucking by hand (Azadirachta indica). They were stored under room temperature in sisal sacks. Crude extracts of single plant (A. indica, T. minuta and $N$. tobacum) were prepared by thoroughly washing leaves and /or flowers or twigs then air-drying them on sterile blotter under shade (Table 3). Within 36 hours after harvesting, a sample of $1 \mathrm{~kg}$ of each of the three plants was blended in waring blender (Waring International, New Hartford, CT, USA) for 10min without distilled water. Individual plant extracts were filtered using Buchner funnel to yield 'concentrated' extract.

The extracts were stored in brown bottles at room temperature until use. The 'concentrated' extracts from $1 \mathrm{~kg}$ plant parts were diluted in 4 litres of water individually and applied to bean crops within 7 days after preparation [20]. Vinca rosea was prepared by adding a proportion of $1 \mathrm{~g}$ (approx. 1 teaspoonful) of oven dried (leaves, flowers and twigs) to $1 \mathrm{ml}$ of sterile distilled water [21]. Control constituted bean plants subjected to spray with Benomyl $1(2.5 \mathrm{~g} / \mathrm{l})$ and distilled water. 


\section{Participatory On-Farm Trials (POFT)}

Participatory On-Farm Trials (POFT) was conducted on 30 farms. The lay out for POFT were based on modified paired-comparison trial approach (Figure 1). Each treatment, strips ran across with dimensions of $25 \times 2.25 \mathrm{~m}$ and replicated 3 times.

Each strip comprised of 2 bean rows and 2 maize rows; the strips were separated from each other with a buffer strip (1 row of beans and 1 row of maize). Within the strip; 1 bean row was subjected to normal dosage and the other double dosage. Intrastrip buffer zone constituted maize row between the two bean strips.

This approach was chosen based on fact that it eliminates field variability effect as a result of nutrient and moisture differences also given that strips lay close to each other; field variability between treatment strips is minimized.

Replications were randomized so as to avoid biasing effects that are not anticipated. The treatments evaluated included Azadirachta indica, Nicotiana tobacum, Vinca rosea, Benomyl 1 and water.

\section{Crude plant extracts application}

First spraying of crude plant extracts commenced upon appearance of $>30 \%$ wilt symptoms, based on disease severity scale $0-4(0=$ no symptoms; $1=1-33 \%$ foliage affected; $2=34-66 \%$ foliage affected; $3=67-100 \%$ foliage affected; $4=$ dead plant) [18], on the control and continued on once a week basis up to second month (Pod forming stage), with application rate of $1000 \mathrm{~g} / \mathrm{l}$ and $2000 \mathrm{~g} / \mathrm{l}$ for four plant extracts; $2.5 \mathrm{~g} / \mathrm{l}$ and $5 \mathrm{~g} / \mathrm{l}$ for Benomyl 1 and spraying was done using hand sprayer [22].

\section{Sampling procedure}

To determine efficacy of plant crude extracts; sample plot of 2 bean rows each measuring $25 \mathrm{~m}$ in length, within row spacing of $25 \mathrm{~cm}$; was used to determine the number of plants showing Fusarium yellows over time with spraying. Data were collected from 3 sample rows in each farm and average value computed. The data were collected at $4^{\text {th }}, 6^{\text {th }}$ and $8^{\text {th }}$ week of weeks after planting (WAP) so as to show trend of plants recovery. Percentage disease incidence was determined using the model: I /Tx100\% where $\mathrm{I}=$ Number of plants showing wilting, $\mathrm{T}=$ total sample plant population.

\section{Minimum Inhibition Concentration (MIC)}

The Minimum Inhibitory Concentration (MIC) of the formulations and Benomyl 1, against Fusarium yellows were determined by the broth microdilution method [23]. The formulations were serially diluted with distilled water to prepare the solutions, with a series of concentrations ranging from 0.5 to $10 \mathrm{mg} \mathrm{ml}^{1}$ per testing well. After

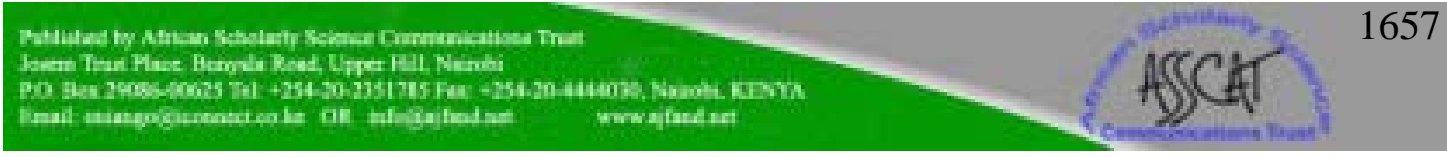


shaking, $4 \mathrm{ml}$ of the antifungal agent solutions were added to the wells of 360 -well plates. The suspension of Fusarium oxysporum was adjusted to $2.5 \times 10^{6}$ spores $/ \mathrm{ml}$ and then $5 \mathrm{ml}$ added to the individual wells and incubated at $24-28^{\circ} \mathrm{C}$. MIC is the lowest concentration that completely inhibited visible fungal growth in the wells after $72 \mathrm{hrs}$ of incubation on observing under compound microscope. Fusarium oxysporum was also cultured with a control solution containing distilled water (-ve control) to certify that it did not affect fungal growth and Benomyl 1 (+ve control); the treatments were performed in triplicate.

\section{Statistical analysis of data}

Analysis of variance (ANOVA) was performed on the data, using Genstat $8^{\text {th }}$ edition statistical program (Release 8.11, Lawes Agricultural Trust, Rothamsted Experimental Station, Harpenden, UK) to identify differences between treatments.

LSD (Least Significant Difference) procedure for comparison of means was applied to separate means $(\mathrm{P}<0.05)$. Treatments differing significantly are indicated in tables by designating different sets of letters.

\section{RESULTS}

\section{Participatory On-Farm Trials (POFT)}

Fusarium wilt incidence in the 30 farms sampled one month $\left(4^{\text {th }}\right.$ week) after planting was recorded to range between $28-31 \%$ ( Figure 1), at this stage of growth bean plants are susceptible to pathogen attack due to tender tissues. Spraying with extracts commenced at $4^{\text {th }}$ week of growth and the incidence significantly reduced at $8^{\text {th }}$ week with continued spraying ( $8^{\text {th }}$ week) to lowest incidence of $10 \%$ as seen in Azadirachta indica. 


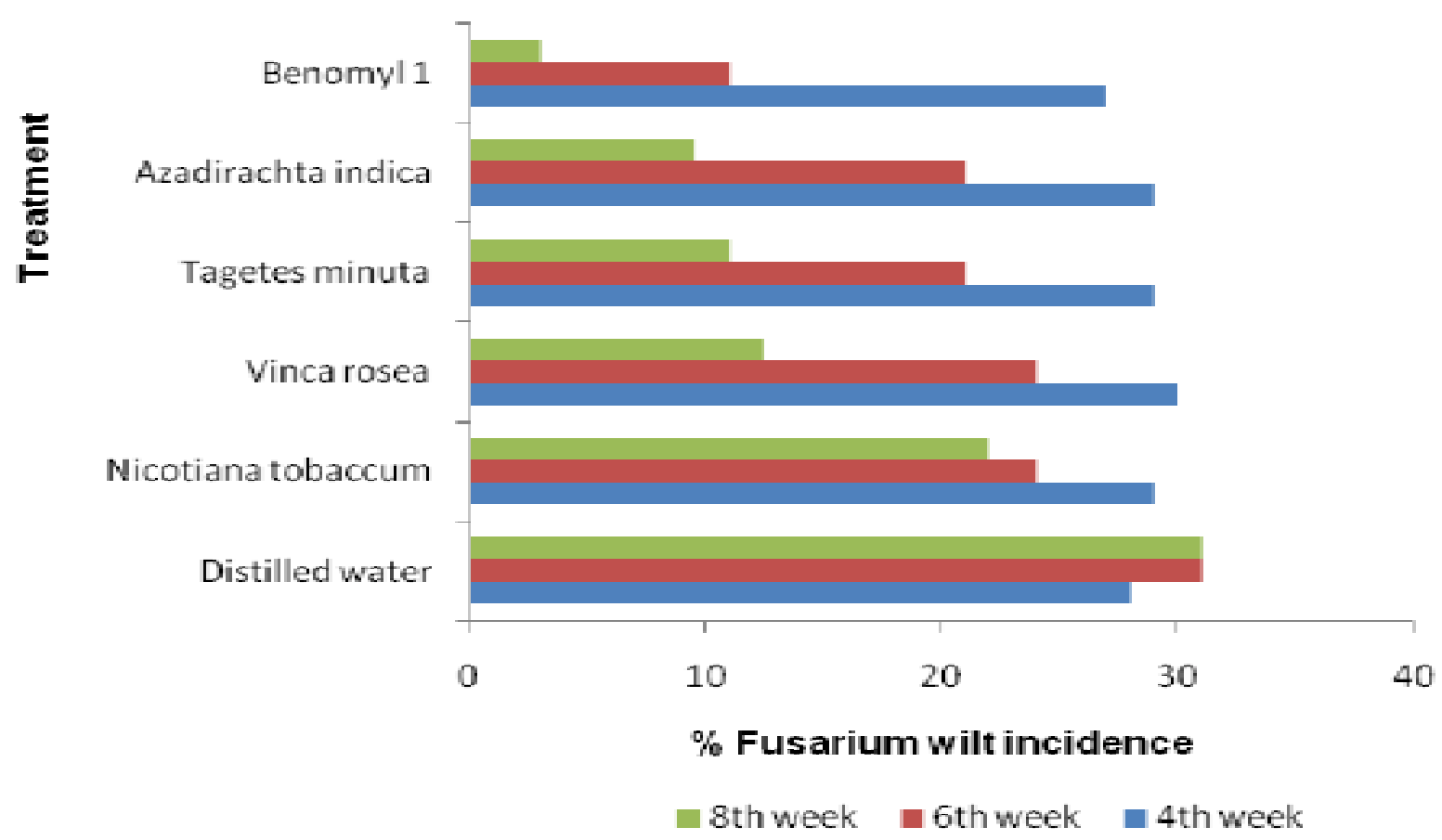

Figure 1: Fusarium yellows incidence overtime with normal spraying regime in farmers fields during March-June 2006 season

Table 1 shows results of Participatory On-Farm Trials in terms of \% Fusarium yellows incidence with spraying over 5 weeks period. Benomyl 1 significantly $(\mathrm{P} \leq 0.05)$ reduced disease incidence in comparison to all other tested treatments. Azadirachta indica performed better amongst all the plant extracts. It reduced the incidence by $17.24 \%$ in comparison to Tagetes minuta, Nicotiana tobacum and Vinca rosea whose \% reduction ranged from 5.84-9.8 considering distilled water as bench mark. Variation in dosage regime (normal/double) did not significantly $(\mathrm{P} \leq 0.05)$ affect disease incidence in the field.

\section{Minimum Inhibitory Concentration (MIC)}

As shown in Table 2 Benomyl 1 exhibited the strongest inhibition against Fusarium yellows with MIC of $1.0 \mathrm{mg} \mathrm{ml} \mathbf{-}^{1}$. The fungicidal activity against Fusarium yellows by Tagetes minuta and Vinca rosea was rated as $5.0 \mathrm{mg} \mathrm{ml}-1$ compared to $10 \mathrm{mg} \mathrm{ml}$ $-{ }^{1}$ for Nicotiana tobacum.

The MIC of Azadirachta indica $2.5 \mathrm{mg} \mathrm{ml}{ }^{1}$ was higher than that of Benomyl 1, however, much lower in comparison to all other plant extracts. This finding suggests that Azadirachta indica is inhibitory to Fusarium growth at lower dosage than Nicotiana tobacum, Tagetes minuta and Vinca rosea with MIC ranging between 5.0 and $10.0 \mathrm{mg} \mathrm{ml}{ }^{1}$. Distilled water did not affect the growth of Fusarium yellows. 


\section{DISCUSSION}

Common bean treatment with fungicide significantly decreased $(\mathrm{P} \leq 0.05)$ the Fusarium yellows incidence and increased the plant growth in comparison to the -ve control. Crude plant extracts from Tagetes minuta, Nicotiana tobacum, Vinca rosea and Azadirachta indica were effective in controlling Fusarium oxysporum with varying degree of efficacy over different growth stages of the bean plants.

Azadirachta indica formulation gave a significant reduction in wilt incidence compared to the other three crude plant extracts formulations. Reports by Achook, Godrej Agrovet Ltd., Mumbai, India, 1999 indicate that a water-soluble Neem formulation containing Azadirachtin, Azadiradione, and a mixture of Nimbocinol and epinimbocinol affects the growth and development of some noctuid larvae or inhibits the growth of phytopathogenic fungi. Neem, as a natural botanical pesticide with a low risk of toxicity to humans and animals, could be one of the important plant protection agents in Integrated Pest Management (IPM) programmes. Studies show that on application as spray; neem is systemically translocated into the plant hence inhibiting mycelial growth in the vascular system [24, 25].

Tagetes minuta performed better in controlling $F$. oxysporum but with lower efficacy in comparison to A. indica. Bioactive extracts from different Tagetes species have been shown to have insecticidal, nematicidal, and fungicidal properties. The main bioactive extract from $T$. minuta is oil consisting mainly of $(Z)$-ocimene $(60 \%)$, followed by dihydrotagetone $(15 \%),(E)$ - and $(Z)$-tagetenones $(12 \%),(E)$ - and $(Z)$ tagetones $(10 \%)$ and sesquiterpenes (2\%) [26]. No previous reports on fungitoxic activity of $T$. minuta could be traced in literature; to date documented information on medicinal properties of $T$. minuta is on its use in pest control initiatives. This study has dealt with the fungitoxic activity of Tagetes minuta and results indicated that it is promising botanical that can be utilized in control of Fusarium yellows.

Although no significant $(\mathrm{P} \leq 0.05)$ difference among $T$. minuta and $V$. rosea against $F$. oxysporum were observed in wilt incidence, putting in consideration other evaluated parameter such as MIC; T. minuta can be rated superior to V. rosea.

Vinca rosea has been documented to posse's fungitoxic characteristics and has been able to control (in-vivo) a number of fungi. Studies on fungitoxic characteristics of $V$. rosea on Helminthosporium modulosum, Sclerotium rolfsii, Pestalotia sp., Fusarium oxysporum, Colletotrichum sp. and Aspergillus niger showed that it inhibited spore germination, sporulation and mycelial growth in some of test fungi (in-vivo) [14]. Growth of $H$. modulosum, S. rolfsii, Pestalotia sp. and Colletotrichum sp. were completely inhibited at $8 \mathrm{ml}$ extract, but $F$. oxysporum and A. niger exhibited growth [20]. Findings from this study concur with results of Narain and Satapathy [1977]; $V$. rosea controlled $F$. oxysporum though at a much higher concentration (MIC of $5.0 \mathrm{mg}$ $\mathrm{ml}^{1}$ ) in comparison to A. indica and Benomyl 1.

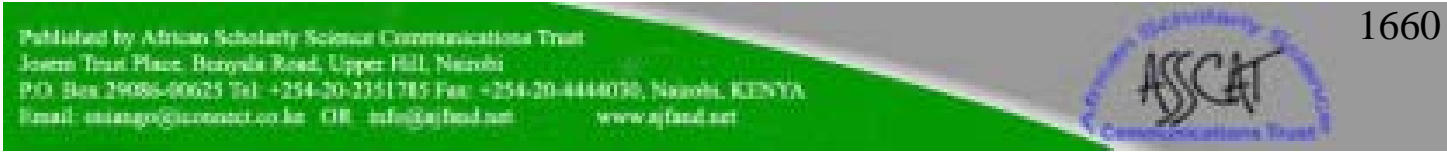


Nicotiana tobacum is known to be highly poisonous due to alkaloid nicotine, a powerful neurotoxin that is particularly harmful to insects. Other active alkaloids in tobacco include Harmala alkaloids. It is also documented to contain nitrosamines and other carcinogenic compounds.

Research on insecticidal activity of tobacco showed that if tobacco powder is used as admixture, it reduces egg laying and hatchability of Callosobruchus maculatus on cowpeas [20]. Research indicates tobacco has insecticidal activity that control Acanthoscelides obtectus Say (Coleoptera: Bruchidae). Little however is documented about its fungitoxic properties against plant pathogens [27]. Results from this study showed that $N$. tobacum formulation did not significantly affect $F$. oxysporum in comparison to -ve control.

\section{CONCLUSION AND RECOMMENDATIONS}

Participatory On-Farm Trials (POFT) showed that crude plant extracts are effective in controlling Fusarium oxysporum Schl. F. sp. phaseoli, with varying degree of efficacy. Spraying with crude plant extracts reduced the incidence of Fusarium in the field and also resulting in complete recovery of initially infected bean plants. Azadirachta indica and Tagetes minuta were found to be the highly effective plant extracts amongst tested crude plant extracts. Besides inhibiting growth of Fusarium in vascular system of the plants they also resulted in low wilt incidence.

In order to institutionalise utilization of these findings in crop production systems and poverty alleviation initiatives; future work should focus on; awareness creation, dissemination of findings, capacity building of both extension staff and community on preparation and conservation of plant sources of these extracts; evaluation of efficacy of combined application of plant extracts and fractionating crude extracts from Tagetes minuta in order to identify the active ingredients responsible for mycelial growth inhibition with view of packaging it as a fungicide will increase its chance of being utilised.

\section{ACKNOWLEDGEMENTS}

Financial support for this study was provided by African Institute for Capacity Development (AICAD), Nairobi, Kenya; contract no. AICAD/05/C/21 which the authors gratefully acknowledge. 
Table 1: Mean Fusarium yellows incidence (\%) for five weeks (Participatory on- Farm Trials)

\begin{tabular}{llcc}
\hline Treatment & Dosage & Incidence $(\%)$ & Difference level \\
& $(\mathrm{g} / \mathrm{l})$ & $($ Mean $\pm \mathrm{SE})$ & 0.05 \\
\hline Water (- ve control) & 500 & $30.47 \pm 2.3$ & $\mathrm{a}$ \\
\hline Nicotiana tobacum & 1000 & $24.63 \pm 2.2$ & $\mathrm{bc}$ \\
\cline { 2 - 4 } & 2000 & $21.57 \pm 1.3$ & $\mathrm{bc}$ \\
\hline Vinca rosea & 1000 & $21.17 \pm 0.9$ & $\mathrm{cb}$ \\
\cline { 2 - 4 } & 2000 & $20.67 \pm 0.7$ & $\mathrm{dc}$ \\
\hline Tagetes minuta & 1000 & $20.67 \pm 0.7$ & $\mathrm{dc}$ \\
\cline { 2 - 4 } & 2000 & $21.63 \pm 0.9$ & $\mathrm{e}$ \\
\hline Azadirachta indica & 1000 & $13.23 \pm 0.7$ & $\mathrm{e}$ \\
\hline Benomyl 1(+ve control) & 2.5 & $15.07 \pm 0.7$ & $\mathrm{f}$ \\
\cline { 2 - 4 } & 2000 & $10.70 \pm 0.3$ & $\mathrm{f}$ \\
\hline & & & \\
\hline & & & \\
\hline
\end{tabular}

Means followed by same letter in column are not significantly different(ns) at $\mathrm{P} \leq 0.05$ 
Table 2: Minimum inhibitory concentration (MIC) of various treatments estimated by broth microdilution method

\begin{tabular}{lc}
\hline Treatment & MIC $^{1}$ \\
& $($ Mean \pm SE) \\
\hline Nicotiana tobacum & $10 \cdot 0 \pm 0.4$ \\
\hline Tagetes minuta & $5 \cdot 0 \pm 0.3$ \\
\hline Vinca rosea & $5 \cdot 0 \pm 0.2$ \\
\hline Azadirachta indica & $2.5 \pm 0.2$ \\
\hline Benomyl 1 & $1.0 \pm 0.1$ \\
\hline MIC $^{1}$ (mg ml ${ }^{1}$ ) mean of 3 replicates &
\end{tabular}

$\mathrm{MIC}^{1}\left(\mathrm{mg} \mathrm{ml}^{\mathrm{I}}\right)$ mean of 3 replicates

Table 3: Plant parts used to prepare extracts

\begin{tabular}{ll}
\hline Plant species & Plant parts used \\
\hline Nicotiana tobacum & Whole plant \\
Tagetes minuta & Whole plant \\
Vinca rosea & Whole plant \\
Azadirachta indica & Leaves/seeds \\
\hline
\end{tabular}




\section{REFERENCES}

1. Mukiibi JM Damage-yield relationship and economic injury levels of podborers and pod sucking bugs on the common bean. In: Proceedings of $2^{\text {nd }}$ African crop science conference, 22-26 ${ }^{\text {th }}$ October 2001 Lagos, Nigeria 2001; 5.

2. Pachico D The demand for bean technology. In G Harry (Ed). Trend in CIAT commodities 1993, CIAT. Cali, Colombia, 1993.

3. Janick J Plant Science: An introduction to world Crops. $3^{\text {rd }}$ edition, W.H. Freeman and Company. New York, USA, 1981.

4. Grisely W An overview of beans production in Sub-Saharan Africa 1970-1989. CIAT regional bean Programme in Eastern Africa, Kampala, Uganda, 1990.

5. Mutitu EW Fusarium yellows of Beans caused by Fusarium oxysporum Schl.f.sp. phaseoli in Kenya. PhD thesis, Nairobi University, 1989. 233pp.

6. District Agriculture Office Busia district monthly Agricultural reports: January 2003-June 2004. DAO, Busia, Kenya, 2004. 60p.

7. Schwartz HF and MS McMillan Occurrence of Fusarium wilt of beans in Colorado. Plant Dis. 1989; 73: 518.

8. El-Abyad MS, El-Sayed MA, El-Shanshoury AR and NH El-Batanouny Inhibitory effects of UV mutants of Streptomyces Corchorus and Streptomyces spiroverticillatus on bean and banana wilt pathogens. Canadian Botanica 1993; 71: 1080-1086.

9. Rusucu G, Buruchara A, Gatabazi M and A Pastor-Corrales Occurrence and distribution in Rwanda of soilborne fungi pathogenic to the common bean. Plant Diseases 1997; 81: 445-449.

10. Pastor-Corrales MA and GS Abawi Reactions of selected bean germplasm to infection by Fusarium oxysporum f. sp. phaseoli. Plant Diseases 1987; 71: 990993.

11. Buruchara RA and $\mathbf{L}$ Camacho Common bean reaction to Fusarium oxysporum $f$. sp. phaseoli, the cause of severe vascular wilt in Central Africa. Phytopathology 2000; 148: 39-45.

12. Lyon GD, Beglinski T and AC Newton Novel disease control compounds: the potential to 'immunize' plants against infection. Plant pathology 1995; 44: 407427.

13. Narain A and JN Satapathy Antifungal characteristics of Vinca rosea extracts In: Indian Phytopathology (Eds). 1977; 30: 36-40. 
14. Ayako AB and K Musambayi Review of poverty in Kenya. Institute of Policy Analysis and Research (IPAR). Nairobi, Kenya, 1997.

15. District Agriculture Office Busia district monthly Agricultural reports: January 2003-June 2006. DAO, Busia, Kenya, 2006. 50p.

16. Togawa M Effect of sterilization methods, plant varieties and leaf stages on conidia and perithecia formation in genus Fusarium in CLA-culture. Trans. Mycology. Society of Japan 1992; 33: 385-393.

17. Cook JA Biological control of plant pathogens overview. In: Biological control in crop production. Beltsville symposia in Agricultural Research. Allanhead Osmun Publishers 1981. pp 23-44.

18. Rebeiro R, Del D and DJ Hagedorn Screening for resistance to end pathogenic specialization of Fusarium oxysporum schl. $f$. sp. phaseoli; the causal agent of bean yellows. Phytopathology 1979; 69 (8): 859-861

19. Snyder WC Antagonism as a plant disease control principle. In: Biological and chemical control of plant and animal pests. American Assoc. for Advancement of science, Washington D.C. 1960. pp 127-136.

20. Agona JA, Owera-Odom F, Kyamanywa S, Silim-Nahdy M and HR Willson Field management of bruchids on beans using selected phytochemicals, insecticides and entomopathogen. In: Proceedings of Integrated Pest Management Conference for Sub-Saharan Africa, Kampala-Uganda $8^{\text {th }}-12^{\text {th }}$ September 2000. 2002; 15: 154-157.

21. Bejarano-Alcázar J, Blanco-López MA, Melero-Vara JM and RM JiménezDíaz Etiology, importance, and distribution Verticillium wilt of cotton in Southern Spain. Plant Diseases 1996; 80: 1233-1238.

22. El-Hassan SA and SR Gowen Formulation and Delivery of the Bacterial antagonist Bacillus subtilis for management of Lentil vascular wilt caused by Fusarium oxysporumf. sp. Lentil. Phytopathology 2006; 154 (3):148-155.

23. Marchetti O, Moreillon P, Glauser MP, Bille J and D Sanglard Potent synergism of the combination of fluconazole and cyclosporine in Candida albicans. Antimicrobial Agents and Chemotherapy 2000; 44: 2373-2381.

24. Vyas BN, Ganesan S, Raman K, Godrej NB and KB Mistry Effects of three plant extracts and achook: a commercial neem formulation on growth and development of three noctuid pests. In: RP Singh and RC Saxena (Eds). Azadirachta indica A. Juss. Oxford and IBH Publishing, New Delhi, India, 1999.

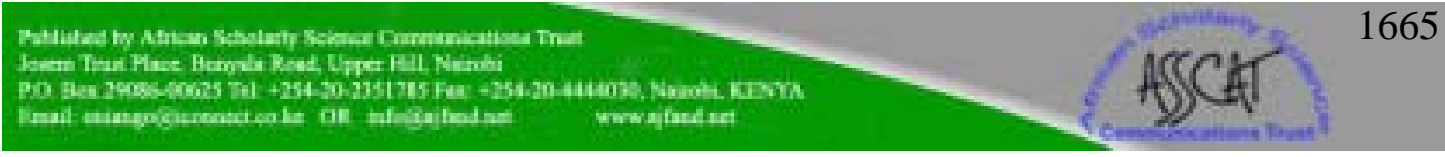


25. Gupta P, Paul MS, Sharma SN and P Gupta Studies on compatibility of white muscardine fungus Beauveria bassiana with some neem products. Indian Phytopathology. 1999; 52: 278-280.

26. Tomova BS, Waterhouse JS and J Doberski The effect of fractionated Tagetes oil volatiles on aphid reproduction. Entomologia Experimentalis et Applicata. 2005; 115 (1): 153-159.

27. Ofunya TI Use of wood ash, dry chilli pepper fruits and onion scale leaves for reducing Callosobruchus maculates (F) damage in cowpea seeds during storage. Journal of Agri. Science, Cambridge. 1989; 107: 467-468. 